\title{
Axillary Metastatic Breast Cancer and Tuberculous Lymphadenopathy in Supraclavicular Region
}

\author{
Özgür Sarıca1 (1), Fatih Ağalar² (1), Kezban Berberoğlu³ (1) \\ 'Department of Radiology, Anadolu Health Center, Breast Center, İstanbul, Turkey \\ 2Department of General Medicine, Anadolu Health Center, Breast Center, İstanbul, Turkey \\ ${ }^{3}$ Department of Nuclear Medicine, Anadolu Health Center, Breast Center, İstanbul, Turkey
}

\section{Cite this article as: Sarıca Ö, Ağalar F, Berberoğlu K. Axillary Metastatic Breast Cancer and Tuberculous Lymphadenopathy in Supraclavicular Region. JAREM 2018; 8: 46-9.}

\begin{abstract}
A healthy assessment of the axilla is a basic requirement in the grading of breast cancer and determining the prognosis. Despite all of the imaging techniques at hand, tissue diagnosis remains to be the gold standard in the assessment of axillary lymphadenopathies in cases with a diagnosis of primary breast tumor. With this presentation, we aimed to discuss our case which seemed to be axillary metastatic lymphadenopathy according to imaging techniques, however supraclavicular tuberculosis lymphadenitis was detected simultaneously with axillary metastatic lymphadenopathy.
\end{abstract}

Keywords: Tuberculosis and breast cancer coexistence, lymphadenopathy, F18-fluorodeoxyglucose, positron emission tomography, ultrasound

ORCID IDs of the authors: Ö.S. 0000-0002-8350-169X; F.A. 0000-0002-6888-0185; K.B. 0000-0002-1796-3239

\section{INTRODUCTION}

Breast cancer recurrence is one of the most important causes of cancer-related mortality. It has been reported that the breast cancer recurrence rate in patients with negative lymph nodes is $30 \%$, and in patients with positive lymph nodes, the rate has been reported as $70 \%$ (1). Granulomatous diseases are known to cause axillary lymph node involvement, and they have been reported in any part of the body as secondary to malignancies (2).

Axillary lymph node metastases are the most important factor affecting the survival of patients with breast cancer (3). Although fluorodeoxyglucose positron emission tomography (FDG PET) is known to have a high specificity in detecting axillary lymph node metastases, high FDG involvement has also been reported in non-tumor specific inflammatory and infectious processes (3). A radiological morphological evaluation, on the other hand, is not specific enough to differentiate malignancy from tuberculous lymphadenitis.

In this report, we argue that the histopathological evaluation of axillary lymph nodes that are considered radiologically suspicious can prevent possible staging errors, as in our case that was diagnosed with primary breast carcinoma.

\section{CASE REPORT}

The examination of our 66-year-old female patient who was admitted to our polyclinic having noticed a mass in her right breast revealed an amorphous $2 \mathrm{~cm}$ palpable mass. The mass was $2 \mathrm{~cm}$ away from the nipple in the right breast. The patient had no known comorbidities. The patient's consent was obtained.

At a 9 o'clock position in the right breast, the mammography showed a solid mass $13 \times 12 \mathrm{~mm}$ in size, which was Category 5 according to the Breast Imaging Reporting and Data System. In the right axilla, several round-shaped malignant formed lymphadenopathies (LAPs), the largest one measuring $9 \times 5 \mathrm{~mm}$ in size, central echogenic with the loss of fatty hilum, were found (Figures 1-3).

On the FDG PET evaluation, the metabolic diameter of the mass was measured to be $12.5 \mathrm{~mm}$, and significant FDG involvement was reported (SUV: 11.2). Abnormal FDG involvement was also noted in two lymph nodes that were situated $8.5 \mathrm{~mm}$ in the right axillary region and $6.5 \mathrm{~mm}$ in the superior region (SUV: 5.8) (Figures 4, 5). Abnormal increased-activity involvements were reported in the lymph nodes in the right supraclavicular region, right anterior mediastinal area, left upper paratracheal, precarinal, bilateral hilar, subcarinal, and paraesophageal areas. The malignant mass and LAPs were evaluated as compatible with malignancy.

The patient was diagnosed with invasive carcinoma after undergoing a Tru-cut biopsy (wide-needle) of the mass in the right breast. It was interpreted as histological grade II (M-SMR), nu- 
clear grade II (Black) ER positive (85\%), PR positive (85\%), HER2 negative, Ki67 score $<14 \%$, and E-cadherin was diffuse positive.

Granulomatous inflammation was reported in the lymph node after performing a Tru-cut biopsy on the pathologic formed lymph node in the right supraclavicular region. In the polymerase chain reaction (PCR) analysis, the DNA of Mycobacterium tuberculosis was detected as positive in the lymph node samples. Pulmonary CT images showed no pulmonary parenchymal lesions that might suggest tuberculosis.

A lumpectomy of the right breast was performed on the patient. A Level 1-2 lymph node dissection was performed on the axilla since the axillary sentinel lymph node biopsy was reported as malignant. A total of 23 lymph nodes were examined, and metastasis was observed in one of them. The size of the largest tumor deposit was measured as $8 \mathrm{~mm}$.

Quadruple antituberculosis therapy was initiated following the lumpectomy and axillary dissection (isoniazid $300 \mathrm{mg}$ 1*1, rifam-

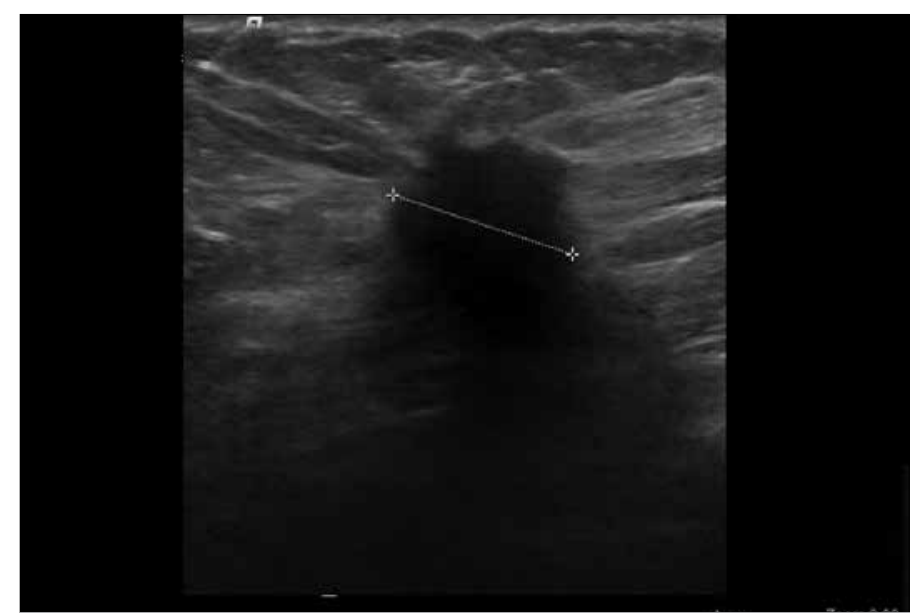

Figure 1. US image of histopathologically confirmed malignant mass in the right breast

US: ultrasonography

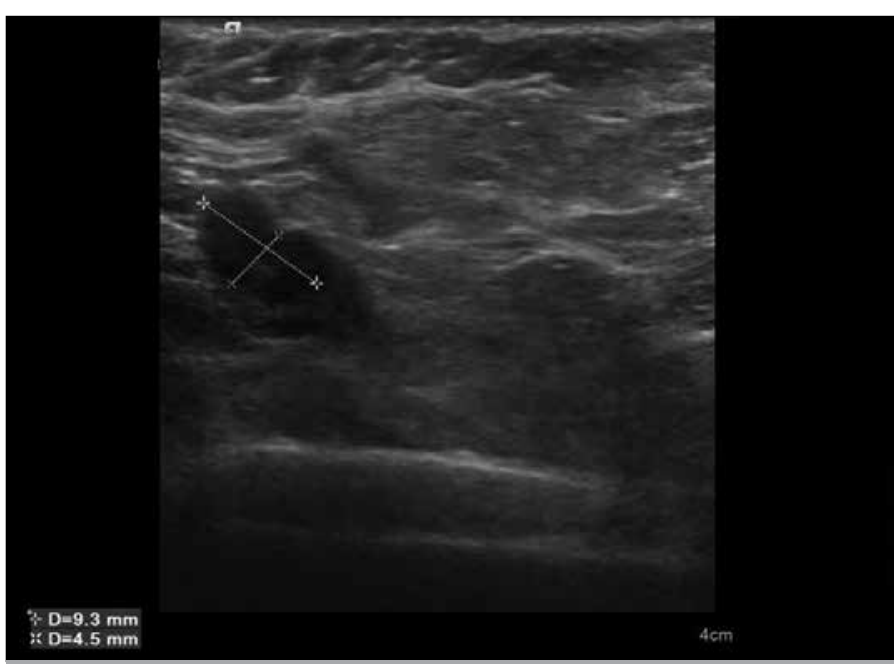

Figure 2. US image of the lymph node considered to be a suspicious malignant lesion showing axillary asymmetric cortical thickening

US: ultrasonography picin 600 mg/day, pyrazinamide 2000 mg/day, ethambulol 1500 $\mathrm{mg} /$ day). Since the patient did not come for a control evaluation, the treatment response could not be assessed.

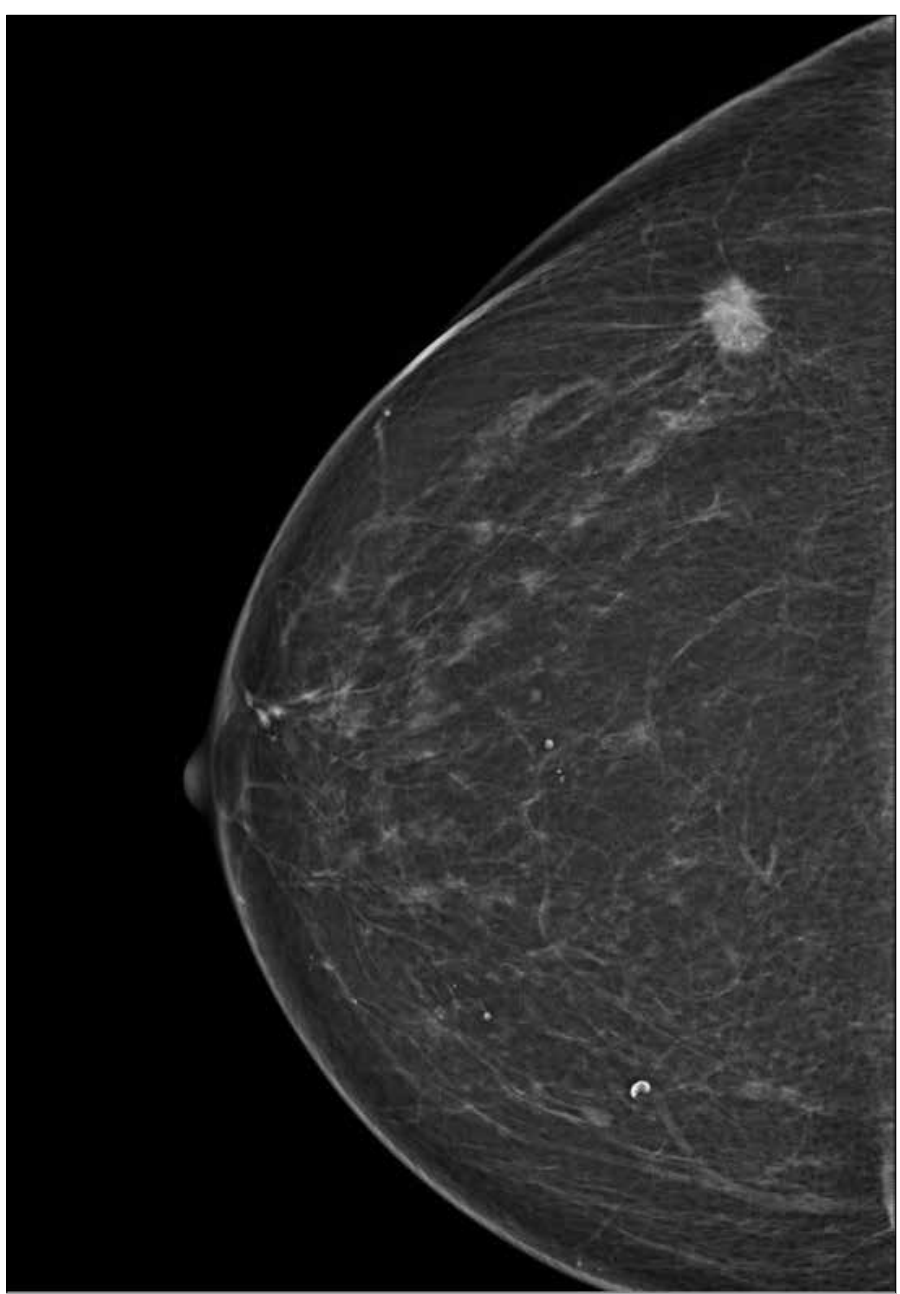

Figure 3. Mammographic image of the mass

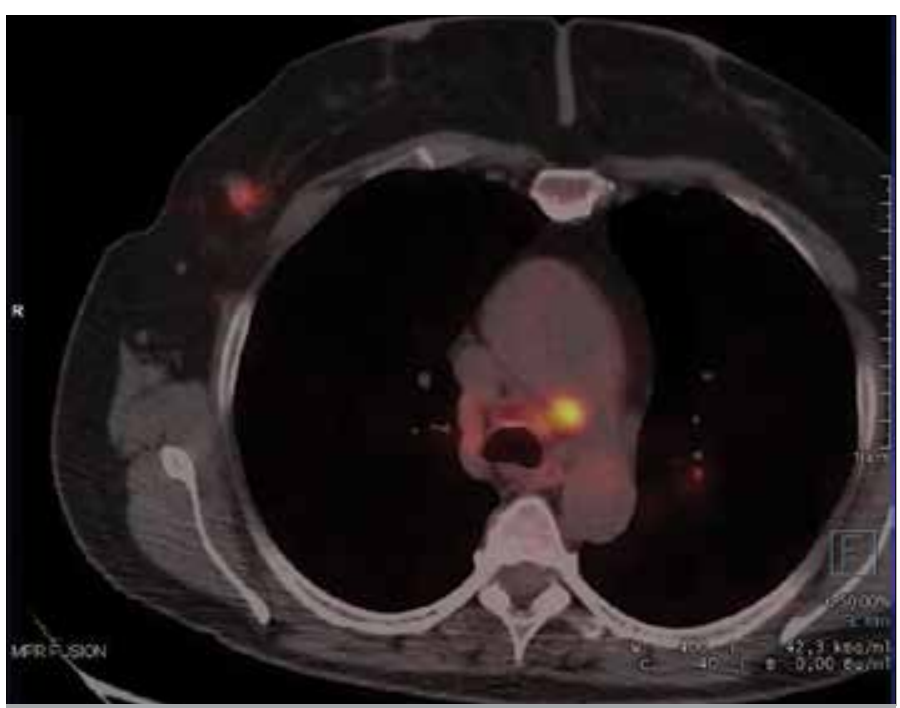

Figure 4. PET-CT fusion images of the mass and mediastinal lymph nodes

PET-CT: positron emission tomography-computed tomography 


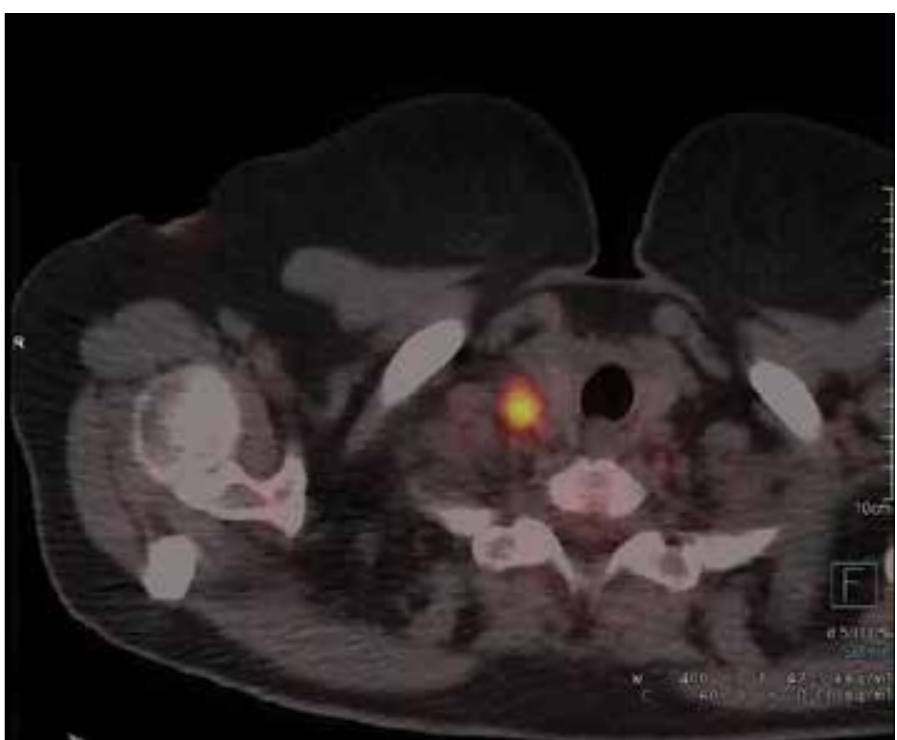

Figure 5. Fusion image of supraclavicular lymph node with high FDG involvement diagnosed with biopsy-confirmed tuberculous lymphadenitis

FDG: fluorodeoxyglucose

\section{DISCUSSION}

Extrapulmonary tuberculosis, $43 \%$ of which showed preliminary findings with peripheral LAP, is the most common form of tuberculous lymphadenitis (4). Just like in our patient's case, in patients with axillary LAP that shows clinical and radiological findings, lymph node involvement may be caused by retrograde propagation from the mediastinal lymph nodes, or by hematogenous propagation from a subclinical focus (5).

It is known that nonspecific granulomatous reactions associated with malignancy are common in cancer patients. In areas such as our country where tuberculosis is endemic, tuberculosis should always be kept in mind in the differential diagnosis of LAP. A wellknown false-positive cause of FDG PET is pulmonary tuberculosis and mediastinal tuberculosis (6).

In the case with primary breast cancer, axillary tuberculous lymphadenitis was reported at the time of diagnosis (7). At the time of the control visits of breast cancer patients who were in complete remission, after the biopsies performed, tuberculous lymphadenitis was reported having FDG-positive recurrent axillary LAP was being detected (8). In our case, since a granulomatous reaction crystallized by caseous necrosis was observed, the problem with the lymph nodes was primarily thought to be associated with tuberculous lymphadenitis during a wide-needle biopsy of the LAPs that displayed increased FDG involvement. Following surgical sampling, a metastatic focus that was $8 \mathrm{~mm}$ in size in the sentinel lymph node was observed.

There are known difficulties in distinguishing metastatic lymph nodes via imaging methods. If the size of the lymph node is smaller than 10 millimeters, the diagnostic success of sonography and magnetic resonance imaging is diminishing. Furthermore, distinguishing infected LAP from metastatic LAP is radiologically challenging. In his study, Özen (9) reported that the sensitivity of PET-CT to detect axillary metastatic LAP was $37 \%-72 \%$, and the specificity was between $89 \%$ and $99 \%$. It is known that LAP caused by tuberculosis is often interpreted as malignant due to the presence of FDG involvement in PET-CT (10). False-positive FDG involvement is mainly due to the FDG involvement of neutrophils and macrophage-containing active granulomatous tissue, fibroblast, and vascular endothelial cells (11). It should be considered that in malign cases, tuberculous lymphadenitis may rarely be observed in the axillary region without any involvement in other organs, and it cannot be ruled out by radiological-metabolic evaluation.

In our case, in the differential diagnosis, idiopathic granulomatous mastitis could be ruled out because of the age of the patient and the absence of the well-known typical radiological and clinical features of idiopathic granulomatous mastitis. The sarcoidosis of the breast, which is rarely reported in the literature, was excluded due to the absence of the lung and ocular involvement. In the PCR analysis, the positive detection of Mycobacterium tuberculosis DNA also excludes other possibilities in terms of laboratory.

There is not enough evidence to suggest that percutaneous biopsy should be performed on all breast cancer cases with axillary lymphadenomas in this study since this is only a case report. In our clinic, after consulting the patient's surgeon, we can also perform axillary sampling, while performing the biopsy on radiologically suspected LAPs of the primary tumor of the breast. However, it should be noted that in many institutions, it may take additional time, and patients may incur additional costs. In breast cancer patients with pathologic lymph nodes in the axilla, conditions such as the presence of uncommonly propagated LAP outside the axillary region, significant mediastinal involvement, or detection of parenchymal pathology accompanied by clinic tuberculosis or tuberculous-suspected parenchymal pathology could be helpful to determine the sampling group.

\section{CONCLUSION}

Axillary lymph node metastases are the most significant factor affecting survival in breast cancer patients and are one of the basic components of the staging system. Although radiologically performed morphologic evaluation and metabolic evaluation through the PET-CT can distinguish metastatic lymph nodes with high accuracy, pathologies that may lead to false-positive evaluation should always be considered, as stated in our case. In our case, LAPs with metastatic and tuberculosis diagnoses were detected in separate levels. Clinically assessed suspected axillary LAPs being preoperatively evaluated via wide-needle tissue and/or fine-needle aspiration biopsy, and with imaging methods, may reduce the false-positive evaluation and morbidity due to surgery.

Informed Consent: Written informed consent was obtained from patient who participated in this study.

Peer-review: Externally peer-reviewed. 
Author Contributions: Concept - F.A.; Design - Ö.S.; Supervision - F.A.; Resources - F.A.; Materials - K.B.; Data Collection and/or Processing K.B.; Analysis and/or Interpretation - Ö.S.; Literature Search - Ö.S.; Writing Manuscript - Ö.S.; Critical Review - Ö.S.

Conflict of Interest: No conflict of interest was declared by the authors.

Financial Disclosure: The authors declared that this study has received no financial support.

\section{REFERENCES}

1. Cardoso F, Castiglione M; ESMO Guidelines Working Group. Locally recurrent or metastatic breast cancer: ESMO clinical recommendations for diagnosis, treatment and follow-up. Ann Oncol 2009; 20: 15-8. [CrossRef]

2. Dorman SE, Guide SV, Conville PS, DeCarlo ES, Malech HL, Gallin $\mathrm{JI}$, et al. Nocardia infection in chronic granulomatous disease. Clin Infect Dis 2002; 35: 390-4 [CrossRef]

3. Peare R, Staff RT, Heys SD. The use of FDG-PET in assessing axillary lymph node status in breast cancer: a systematic review and meta-analysis of the literature. Breast Cancer Res Treat 2010; 123: 281-90. [CrossRef]

4. Dandapat MC, Mishra BM, Dash SP, Kar PK. Peripheral lymph node tuberculosis: a review of 80 cases. Br J Surg 1990; 77: 911-2. [CrossRef]
5. Avninder SP, Saxena S. Infiltrating ductal carcinoma of the breast, metastatic to axillary lymph nodes harboring primary tuberculous lymphadenitis. Pathol Oncol Res 2006; 12: 188-9. [CrossRef]

6. Lee JW, KimBS, Lee DS, Chung JK, LeeMC, KimS, et al. 18F-FDG $\mathrm{PET} / \mathrm{CT}$ in mediastinal lymph node staging of non-small-cell lung cancer in a tuberculosis-endemic country: consideration of lymph node calcification and distribution pattern to improve specificity. Eur J Nucl Med Mol Imaging 2009; 36: 1794-802. [CrossRef]

7. Akbulut S, Sogutcu N, Yagmur Y. Coexistence of Breast Cancer and Tuberculosis in Axillary Lymph Nodes: A Case Report and Literature Review. Breast Cancer Res Treat 2011; 130: 1037-42. [CrossRef]

8. Ataergin S, Arslan N, Ozet A, Ozguven MA. Abnormal FDG uptake on 18F-fluorodeoxyglucose positron emission tomography in patients with cancer diagnosis: case reports of tuberculous lymphadenitis.Intern Med 2009; 48: 115-9. [CrossRef]

9. Özen A. The Evaluation of Primary Lesion and Axillary Metastasis in Breast Carcinoma By 18F-FDG PET/CT. J Clinic Anal Med 2015; 1-6.

10. Alan Selçuk N, Fenercioğlu A, Selçuk HH, Uluçay C, Yencilek E. Multifoci Bone Tuberculosis and Lymphadenitis in Mediastinum Mimics Malignancy on FDG-PET/CT: A Case Report. Mol Imaginig Radionucl Ther 2014; 23: 39-42. [CrossRef]

11. Yamada S, Kubota K, Kubota R, Ido T, Tamahashi N. High accumulation of fluorine-18-fluorodeoxyglucose in turpentineinduced inflammatory tissue. J Nucl Med 1995; 36: 1301-6. 